
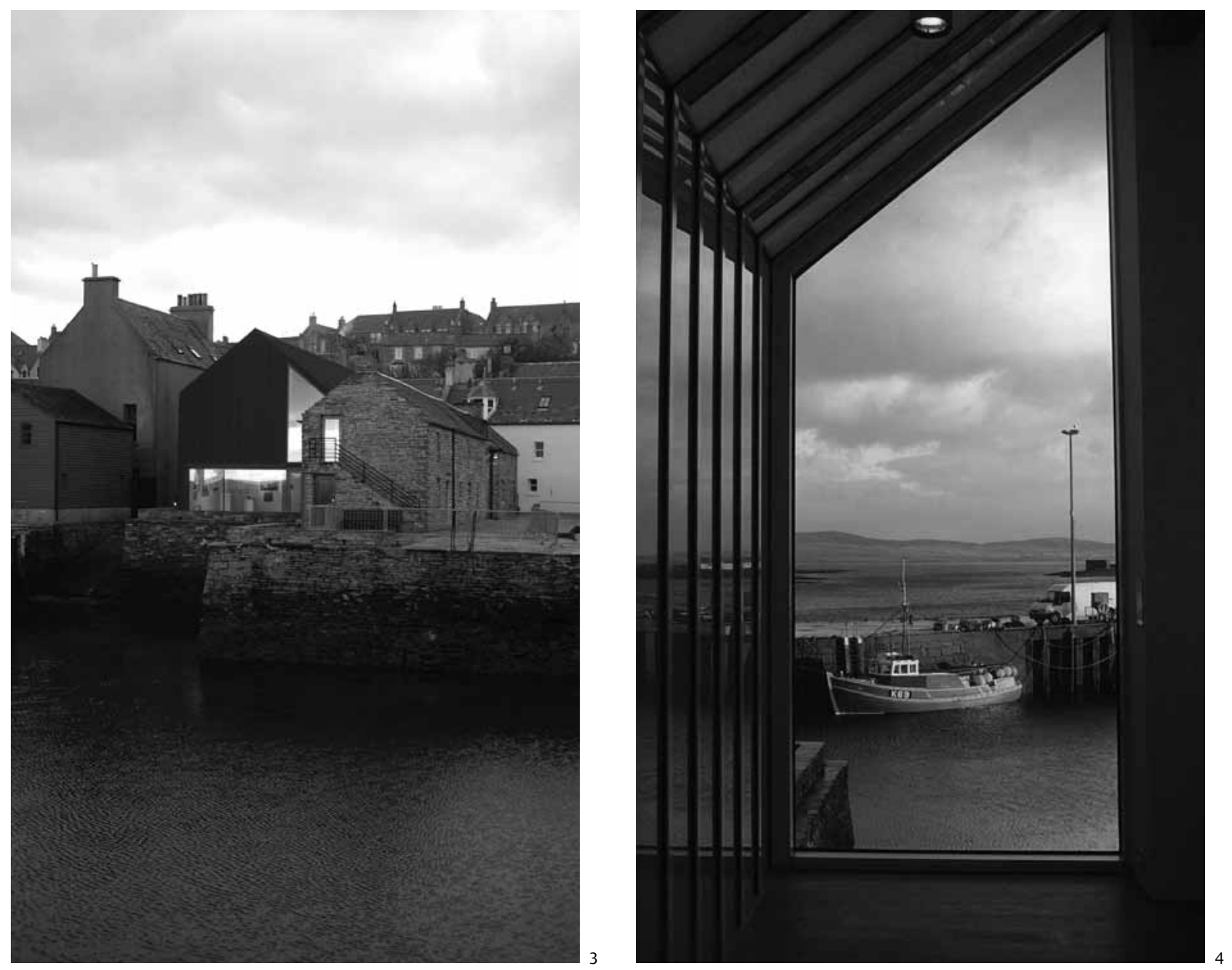

3-4 The 'craft and sensitivities' of Reiach and Hall's Pier Arts Centre,

Stromness, in 'the most secure of contexts'

paradox that, given its remoteness, Stromness is almost unbearably intense in its urbanism. The article describes the building as having a dialogue between a charged, intensely local context and an outward looking internationalism. It is, all told, very much a utopian manifestation of the north. We have in Hourston Hanks' paper a lucid, sensitive exposition of Reiach and Hall's great skill in crafting a fine building. Where I think we need to look further is what can be learnt to design elsewhere in a Scots landscape less blessed with such strong cultural and spatial cues. The recent competition for $\mathrm{V} \& \mathrm{~A}$ Dundee shows how, when cut loose from its host city, the iconic architecture of the 'destination' building takes hold. The unpacking of the Pier Arts Centre illuminates craft and sensitivity, but is tested in the most secure of contexts.

JOHN BRENNAN Edinburgh

John Brennan is a practising architect and Senior Lecturer at the Edinburgh School of Architecture and Landscape Architecture

\section{Broadening entry to the profession}

Architecture is not an invisible profession. Conversely, unlike other construction-related professional areas, architecture is very visible in the minds of the public. It is often mentioned in the same breath as law and medicine as one of the elite professional areas that a highflying student might aspire to join. Consequently the need to raise the profile of the profession in the minds of students to encourage applicants to architecture courses does not seem to apply when considering whether there is value in developing an A-level in Architecture as described by Robert Atkinson (arq, 14.3, pp 267-76).

This A-level course has been running at Richmond upon Thames College since 2001 and has attracted over a hundred students in the last three academic years. It is clearly a popular course, but is it valuable? Atkinson puts forward three main points to support the value of this A-level, but in my view one significant point that will emerge from this discussion is missing from his supporting argument.

Atkinson's first point is that the A-level in Architecture provides an appropriate qualification for students wishing to enter an architecture course at a UK university and enables students to prepare a portfolio of work to present at interviews. The cost of organising interviews in terms of staff time and the pressure on universities to cut costs especially in relation to what are regarded as expensive courses to run means that a large percentage of universities do not call students to interview. Reliance on A-level predictions and final achievement is consequently very strong. In consequence it is significant to look at the way in which universities regard different A-levels. Atkinson relies on the lack of evidence to support the contention that an Architecture A-level will not be as highly regarded as more traditional academic subjects. Bath University's list of subjects that are seen as 'less effective preparation' (LEPs) for the study of Architecture, is cited by Atkinson as evidence that the 
A-level is accepted by Schools of Architecture simply because the list does not include the A-level in Architecture in its list. However, it seems questionable whether an A-level in Architecture will be as highly regarded by the admissions tutors at many universities as more conventional academic subjects such as Maths, Physics, History or English. With only anecdotal evidence to support the assumption that the A-level in Architecture will be well received, it is difficult to make a specific pronouncement on this point.

Universities are inclined to be cagey about how they make decisions and offer or decline places to students. However, if asked to advise a young person with high aspirations about suitable A-levels to take, my own instincts and those of many colleagues, would be to advise conventional academic subjects. This advice would almost certainly apply to students who had made up their minds to be architects and to those who had yet to make a definite career choice, particularly if their aspirations favoured a Russell Group university. For students who have not finally decided their career options, particularly in the competitive climate emerging from the changing fee structure and the implementation of the Browne Review's findings, the choice of Architecture at A-level may even be a dangerous strategy if they finally decide to opt to study a conventional degree subject.

Atkinson himself raises the question about whether a university education that lasts for seven years needs any additional preparation by students at the A-level stage. While the thoughtful and analytical approach to the curriculum described by Atkinson in his role as tutor on the Richmond A-level course appears to be well defined and pays close attention to the development of knowledge, skills and understanding, it is likely that other traditional subjects would also develop these characteristics and possibly help to broaden the minds of future architectural students. Concerns about early specialisation are often levelled at the UK education system; is it necessary to take this specialisation to an even earlier stage in a student's career path?

Notwithstanding these concerns, there are many aspects of Atkinson's curriculum that sound like a dream scenario for a more general education on design matters that could be extended more widely. The argument that an architectural education is beneficial in its own right is an interesting one. Of course, people who have experienced such an education themselves are likely to see this through rose-tinted spectacles. The same argument may well be advanced by

mathematicians who point to the beauty and the mind training of numbers, or historians who feel that in-depth understanding and analytical skills are enhanced by a study of the past. Nevertheless, countless commentators have bemoaned the lack of design understanding in the general population and the impact that this has on the built environment. Uninformed clients for new development are almost certainly one of the reasons for the poor quality of too much of the built environment. Consequently, it is tempting to welcome the fact that at least 100 students per year are having their design awareness raised; even if they subsequently enter other career paths. However, the argument for incorporating more design awareness into the curriculum is one that should be advanced to ensure that all students, and not just a handful, who opt to study an A-level in Architecture, should receive a basic design education. The UK's coalition government is currently rethinking GCSE and A-level curricula and the time is right to lobby to address the shortfall in public understanding of the need for design quality, not just in terms of built form, but in terms of the design of all products. Enhanced quality in design could benefit the economy and make the UK recognisable as a marketplace for high quality goods and services as well as built environments.

Turning at last to what might be an even stronger argument for this A-level than the ones advanced is the impact the course may have on the aspirations of young people who may have received the message that architecture is not for them. Architects for Change (AFC), the RIBA's Equality forum, are aware of the fact that the profession is not diverse and not representative of the population it serves.

Encouraged by AFC, the RIBA commissioned research into the reasons why women were leaving the profession. ${ }^{15}$ The findings of this research were not dissimilar to other work that looked at the experiences of many black and minority ethnic architects who had, in common with women, felt excluded and sidelined in the profession. More recent research for the RIBA carried out by Manley and de Graft-Johnson on the experiences of disabled people in the profession, reinforces the idea that architecture is widely regarded as a high profile profession that is mainly suited to white, middle-class males and not open to everyone. A recent contributor to this research commissioned by the RIBA in 2008 and soon to be published, commented:

The school careers advisor said I wouldn't cope because of I was $d y$ slexic and suggested being $a$ plumber or an electrician. Two occupations I don't look down on in any way but neither were careers I personally wanted to pursue. Another disabled person who had the potential to be an architect was discouraged by everyone, '... on the basis that I am a woman and would be having children. On the basis that it is a profession for the upper classes and not for the likes of us'.

These reports from respondents seem to imply that in spite of changes for the better, the impression given to many young people with potential is that the profession is not an appropriate one for them. Atkinson does not comment on the gender balance on the Richmond A-level course or on whether the course includes students from lower income groups or from families with no tradition for higher education, but it does seem to have a significant mix of people from different ethnic backgrounds. If indeed the course provides entry routes for students from a broader range of backgrounds then it will have proved itself of real value.

SANDRA MANLEY Bristol

Sandra Manley is Principal Lecturer at the School of Built and Natural Environment, University of the West of England, Bristol

\footnotetext{
Ask not what schools can do for us; ask what we can do for schools For years I have bemoaned the absence of architectural education in schools. As I have intimated elsewhere, I believe there is an architect in everyone. The success of television programmes on 'Grand Designs' and house renovation seems to support the case. In that architecture provides the setting for just about everything we do in our lives - from the labour ward to the crematorium - it is as culturally
} 